\title{
Hypertension and associated factors in the Islamic Republic of Iran: a population-based study
}

\author{
Marzieh Katibeh, ${ }^{1,2}$ Ali Moghaddam, ${ }^{3}$ Mehdi Yaseri, ${ }^{4}$ Dinesh Neupane, ${ }^{2}$ Per Kallestrup ${ }^{2}$ and Hamid Ahmadieh ${ }^{3}$
}

${ }^{1}$ Ophthalmic Epidemiology Research Center, Shahid Beheshti University of Medical Sciences, Tehran, Islamic Republic of Iran. ${ }^{2}$ Center for Global Health, Department of Public Health, Aarhus University, Aarhus, Denmark. ${ }^{3}$ Ophthalmic Research Center, Shahid Beheshti University of Medical Sciences, Tehran, Islamic Republic of Iran (Correspondence to: A. Sanjari Moghaddam: alisanjarimoghaddam@yahoo.com). ${ }^{4}$ Department of Epidemiology and Biostatistics, School of Public Health, Tehran University of Medical Sciences, Tehran, Islamic Republic of Iran.

\begin{abstract}
Background: Hypertension is a major risk factor for cardiovascular diseases and has a high prevalence in the Eastern Mediterranean Region.

Aims: To estimate the prevalence and awareness of hypertension and its associated factors in a central province of the Islamic Republic of Iran.

Methods: This cross-sectional study was conducted among 2320 adults aged 40-80 years in Yazd, Islamic Republic of Iran, in 2010-2011. Multivariable logistic regression analysis was performed to calculate the odds ratios (ORs) for exploring the association between hypertension and associated risk factors. Of eligible subjects, 2098 participated in clinical examinations (response rate: 90.4\%).

Results: The sex- and age-standardized prevalence of hypertension was 52.8\% [95\% confidence interval (CI): 49.6-56.1\%]. Of 1170 participants with hypertension, 421 were diagnosed for the first time in this survey; therefore, the unawareness proportion was $36.0 \%$ (95\% CI: 33.2-38.8\%). Among known cases (749 of 1170), 68.5\% (95\% CI: 65.0-71.8\%) had uncontrolled blood pressure. Age (OR 70-80 vs. 40-50 years=7.01, 95\% CI: 4.01-12.24), obesity (OR=2.78, 95\% CI: 2.06-3.75), diabetes $(\mathrm{OR}=1.46,95 \% \mathrm{CI}: 1.12-1.89)$, hyperlipidaemia (OR=1.60, 95\% CI: 1.26-2.03) and living in a rural area (OR=1.57, 95\% CI: 1.02.45) were significantly associated with hypertension.

Conclusions: Although age is an inevitable risk factor for hypertension, the high unawareness proportion, uncontrolled hypertension and modifiable risk factors such as obesity, hyperlipidaemia and diabetes demand effective preventive and curative strategies.

Keywords: hypertension, Islamic Republic of Iran, prevalence, risk factors

Citation: Katibeh M; Sanjari Moghaddam A; Yaseri M; Neupane D; Kallestrup P; Ahmadieh H. Hypertension and associated factors in the Islamic Republic of Iran: a population-based study. East Mediterr Health J. 2020;26(3):304-314. https://doi.org/10.26719/emhj.19.042

Received: 14/04/17; accepted: 04/07/18

Copyright (C) World Health Organization (WHO) 2020. Open Access. Some rights reserved. This work is available under the CC BY-NC-SA 3.o IGO license (https://creativecommons.org/licenses/by-nc-sa/3.o/igo).
\end{abstract}

\section{Introduction}

Hypertension is a major risk factor for cardiovascular diseases, including coronary heart disease, heart failure, arrhythmia and cardiomyopathy. There is also an increased risk of chronic kidney disease and stroke among hypertensive patients $(1,2)$. According to The Global Burden of Disease Study, hypertensive heart disease accounted for 17.5 million disability-adjusted life years in 2015 (3). Research-based evidence has demonstrated an increased risk of hypertension with older age, male sex, and hyperlipidaemia (4).

The World Health Organization (WHO) reported that $30.7 \%$ of men and $29.1 \%$ of women in the Eastern Mediterranean Region were estimated to have hypertension in 2008 (5). The prevalence of hypertension in the Islamic Republic of Iran among adults aged $>25$ years was estimated at $31 \%$ in men and $27 \%$ in women. Previous studies conducted in different provinces of the Islamic Republic of Iran (6-8) showed a large variation of hypertension prevalence among different provinces. A study in Yazd revealed that $53.7 \%$ of people with hypertension were aware of their disorder, $24 \%$ of them were under treatment, and only $8 \%$ had controlled hypertension (7). As prevalence of hypertension is probably increasing in low- and middle-income countries (9) including the Islamic Republic of Iran (10), it is important to conduct additional studies to evaluate the trends and associated factors. In addition, population-based surveys on prevalence and risk factors of hypertension are important in settings where routine health monitoring systems are not in place. Due to limited research resources in these settings, most studies of hypertension are performed at subnational level; therefore, collecting data from different geographic areas may be more practical and can later be combined to give a more general picture of hypertension in a country or region. The aim of this study was to estimate the prevalence, awareness and associated factors of hypertension in a central district of the Islamic Republic of Iran.

\section{Methods}

\section{Study population}

The present study was part of a multidimensional population-based study, as described previously (11). This cross-sectional study was conducted in an urban and 
rural area of Yazd District, Islamic Republic of Iran in 2010-2011. The sample size was 2320 adult residents of Yazd aged 40-80 years, who were recruited with a systematic cluster sampling method. The Ethics Committee of Shahid Beheshti University of Medical Sciences, Tehran, Islamic Republic of Iran approved the study protocol. Written informed consent was obtained from the participants prior to data collection.

\section{Data collection}

A general practitioner conducted general medical assessments including blood pressure measurement. After 5 minutes of rest, blood pressure was taken using a standard mercury sphygmomanometer (nova-presameter; Riester, Jungingen, Germany) in a sitting position twice at the same session and the average measurement was recorded. Fasting blood sugar (FBS) was measured first during the home visit using a glucometer (ACCU CHEK Active Meter; Roche Diagnostics, Indianapolis, IN, USA). A complete blood test from the venous blood sample was conducted after overnight fasting prior to blood sampling at a standard laboratory to measure FBS, haemoglobin Alc and lipid profile. Body weight was measured with indoor clothing using a Balas Miracle Scale (Karaj, Islamic Republic of Iran) and standing height was measured without shoes using a measuring rod (Balas). In addition, self-reported information on tobacco use, physical activity and education level was collected.

\section{Definitions}

Hypertension was defined according to the definitions of the Joint National Committee 7 (JNC 7) as: (1) systolic blood pressure (SBP) $\geq 140 \mathrm{mmHg}$ and/or diastolic blood pressure (DBP) $\geq 90 \mathrm{mmHg}$ (12); or (2) self-reported history of hypertension and/or taking any antihypertensive medication. A summary of blood pressure definitions that

\begin{tabular}{|c|c|c|}
\hline \multicolumn{3}{|c|}{ Total study population } \\
\hline SBP/DBP mmHg & $\begin{array}{c}\text { Antihypertensive } \\
\text { medication }\end{array}$ & Considered status \\
\hline \multirow{2}{*}{$<120 / 80$} & No & Normotensive \\
\hline & Yes & Hypertensive \\
\hline \multirow{2}{*}{$120-139 / 80-89$} & No & Prehypertensive \\
\hline & Yes & Hypertensive \\
\hline \multirow{2}{*}{$\geq 140 / \geq 90$} & No & Hypertensive \\
\hline & Yes & Hypertensive \\
\hline \multicolumn{3}{|c|}{ Participants with newly diagnosed hypertension } \\
\hline \multirow{2}{*}{$\begin{array}{l}140-159 / 90-99 \\
\geq 160 / \geq 100\end{array}$} & & Stage I hypertension \\
\hline & & Stage II hypertension \\
\hline \multicolumn{3}{|c|}{ Participants with known hypertension } \\
\hline$<140 /<90$ & & $\begin{array}{l}\text { Controlled } \\
\text { hypertension }\end{array}$ \\
\hline$\geq 140 / \geq 90$ & & $\begin{array}{l}\text { Uncontrolled } \\
\text { hypertension }\end{array}$ \\
\hline
\end{tabular}

were used in this study is presented in Table 1 . Diabetes mellitus was defined as two independent FBS measurements $\geq 126 \mathrm{mg} / \mathrm{dl}$ (7.0 mmol/l), and/or previous history of diabetes diagnosed by a physician, and/or glucose lowering agent medication. Hyperlipidaemia was based on lipid profile in a fasting blood sample, that is, triglyceride $>150 \mathrm{mg} / \mathrm{dl}$ (1.7 mmol/l), low-density lipoprotein > 130 $\mathrm{mg} / \mathrm{dl}$ (3.4 mmol/l), high-density lipoprotein < $35 \mathrm{mg} / \mathrm{dl}$ (0.9 mmol/l), cholesterol > $150 \mathrm{mg} / \mathrm{dl}$ (3.9 mmol/l), previously diagnosed by a physician, or taking lipid lowering medication. For BMI, participants were classified into 3 groups: normal weight, overweight $(25 \leq \mathrm{BMI}<30 \mathrm{~kg} /$ $\left.\mathrm{m}^{2}\right)$ and obese $\left(B M I \geq 30 \mathrm{~kg} / \mathrm{m}^{2}\right)$. Age of participants was recorded according to their birth certificate and it was measured as the number of full years they had lived at the time of study enrolment. In addition, age was categorized into 4 10-year intervals of 40-49, 50-59, 60-69 and $70-80$ years old. Education was based on number of complete years of formal education and it was categorized as illiterate, incomplete primary education ( $<6$ years), primary to secondary education (6-12 years), and higher education at a college or university. Physical activity was defined as any kind of regular exercise at least 3 times per week or having physically active occupations.

\section{Statistical analysis}

The sex and age standardized prevalence of hypertension was calculated considering demographic composition of people aged 40-80 years who lived in the survey area based on the National Census 2006. In evaluation of the relations, we considered the clustering effect by multilevel analysis within logistic regression. First, we evaluated the univariate relations in a simple multilevel logistic regression. Then, to consider the clustering effect and confounders in the evaluation of the relations, we used multilevel multivariable logistic regression. In this model age, sex, education, diabetes, smoking, BMI, hyperlipidaemia, physical activity and living area were independent variables and covariates (for other variables in the model). The main outcome (dependent) variable was a binary variable with 1 for hypertension and o for not hypertension. We used similar models for other outcome measurements including awareness, control status, and stage of hypertension. Within these models, we calculated adjusted odds ratios (ORs) to evaluate association of different factors with hypertension and other outcomes. We considered duration of smoking and amount of smoking as quantitative variables and all other variables were considered as categorical variable in all models. $P<0.05$ was considered statistically significant at $95 \%$ confidence intervals (CIs). We used Stata version 12.0 for statistical analysis.

\section{Results}

Of 2320 invited residents, 2098 participated (response rate: $90.4 \%$ ) with a mean age (standard deviation) of 54.1 (10.0) years. Eighty-nine percent of the study population were urban dwellers and 53\% were women. Among participants, $15.7 \%$ reported a history of smoking and $\sim 20 \%$ had no 
level of education. The mean BMI was 27.4 (4.7) $\mathrm{kg} / \mathrm{m} 2$ and nearly $25 \%$ of participants had a physically active lifestyle. The crude proportion of diabetes and hyperlipidaemia was $25.8 \%(n=539)$ and $34.4 \%(n=731)$, respectively. Prevalence of hypertension and more details of participants' characteristics are provided in Tables 2 and 3.

Age- and sex-standardized prevalence of hypertension and prehypertension was 52.8\% (95\% CI: 49.6-56.1\%) and $35.1 \%$ (95\% CI: 31.9-38.4\%), respectively (Table 2). Of these, $19.5 \%$ (95\% CI: $17.4-21.7 \%$ ) were newly diagnosed with hypertension and among known cases, 68.5\% had uncontrolled blood pressure ( $\geq 140 / 90 \mathrm{mmHg}$ ).

Urban dwellers had a hypertension prevalence of $54.4 \%$, while prevalence of hypertension among rural residents was $67 \%$ (Table 3 ). Prevalence of hypertension among illiterates was $74.2 \%$, while $45.7 \%$ people with > 12 years of education had hypertension. Prevalence of hypertension was greater in non-smokers (58.1\% vs. $43 \%$ ). Among individuals with normal BMI, just $48.5 \%$ had hypertension, whereas $69 \%$ of obese participants had hypertension. Prevalence of hypertension in patients with hyperlipidaemia and diabetes was $69.6 \%$ and $70.1 \%$, respectively.

By sex, prevalence of hypertension was $52 \%$ in men and $59.1 \%$ in women. Prevalence of hypertension was higher in women, but hypertensive men were more likely to have undiagnosed hypertension. Prevalence of hypertension increased with age in both sexes. Prevalence of hypertension among men and women aged 40-49 was $33.7 \%$ and $41.4 \%$ and this increased to $54.7 \%$ for men and $63.8 \%$ for women aged 50-59 years, $66.8 \%$ for men and $79.2 \%$ for women aged $60-69$ years, and $69.7 \%$ for men and $89.9 \%$ for women aged $70-80$ years.

Older age, obesity, diabetes, hyperlipidaemia and living in a rural area were significantly associated with hypertension (Table 4). In addition, older people, women, people with diabetes, and people with hyperlipidaemia were more aware of their hypertension. Uncontrolled hypertension was significantly higher in age group 6069 years and in people with diabetes. Age had a strong relationship with hypertension, in that people aged 70-
80 years had $>7$-fold odds of hypertension compared to those aged 40-50 years. On the contrary, we did not find a significant association between hypertension and the sexes, physical activity, level of education or smoking (Table 4).

\section{Discussion}

We measured prevalence of hypertension and its associated factors in a central district of the Islamic Republic of Iran. Age- and sex-standardized prevalence of hypertension in this representative sample of the population aged 40-80 years in Yazd was 52.8\%. Previous studies reported a wide range of hypertension prevalence in the Islamic Republic of Iran, ranging from $7.21 \%$ among 7-12-year-old children in Ghazvin Province (13) to $41.8 \%$ in 40-75-year-old residents in Golestan Province (6). A systematic review of 29 studies in the Islamic Republic of Iran in 1996-2004 reported prevalence of hypertension around $50 \%$ in the population aged $\geq 55$ years (10). A recent study in Yazd Province revealed that prevalence of hypertension in men and women aged $20-74$ was $27.6 \%$ and $23.9 \%$, respectively (7). The higher percentage of hypertension in our study was probably due to the older age of the study population.

Hypertension is a common health problem and its prevalence is increasing in low- and middle-income countries. Migration to urban areas, population ageing, dietary patterns and stressful lifestyles are reasons for the increasing prevalence (9). As observed in the current study, age is a strong independent risk factor for hypertension (14) and might have resulted in the higher prevalence of hypertension in our study compared to others. A study among people aged $\geq 65$ years in Taiwan reported prevalence of $60.4 \%$ hypertension (15). Table 5 compares prevalence of hypertension in different studies by sex and age.

In our study, prevalence of hypertension was higher among women; however, the association was not significant after adjusting for confounders. According to WHO, total prevalence of hypertension is globally higher among men (5). Similarly, studies conducted in

\begin{tabular}{|c|c|c|c|c|c|c|c|}
\hline \multicolumn{8}{|c|}{ Table 2 Crude and standardized prevalence of hypertension } \\
\hline & & & & & & Lower & Upper \\
\hline \multicolumn{3}{|l|}{ Normal } & 231 & $11.0 \%$ & $12.0 \%$ & $9.5 \%$ & $14.6 \%$ \\
\hline \multicolumn{3}{|l|}{ Prehypertension } & 697 & $33.2 \%$ & $35.1 \%$ & $31.9 \%$ & $38.4 \%$ \\
\hline \multirow[t]{7}{*}{ Hypertension } & & & 1170 & $55.8 \%$ & $52.8 \%$ & $49.6 \%$ & $56.1 \%$ \\
\hline & New case & & 421 & $20.1 \%$ & $19.5 \%$ & $17.4 \%$ & $21.7 \%$ \\
\hline & & Stage I & 106 & $5.1 \%$ & $5.0 \%$ & $3.8 \%$ & $6.1 \%$ \\
\hline & & Stage II & 315 & $15.0 \%$ & $14.6 \%$ & $13.0 \%$ & $16.2 \%$ \\
\hline & Known & & 749 & $35.7 \%$ & $33.3 \%$ & $30.7 \%$ & $35.9 \%$ \\
\hline & & Controlled & 188 & $9.0 \%$ & $8.5 \%$ & $7.1 \%$ & $9.8 \%$ \\
\hline & & Uncontrolled & 513 & $24.5 \%$ & $22.5 \%$ & $19.8 \%$ & $25.2 \%$ \\
\hline
\end{tabular}

aSex-and age-standardized prevalence of hypertension based on the National Census 2006. CI = confidence interval. 


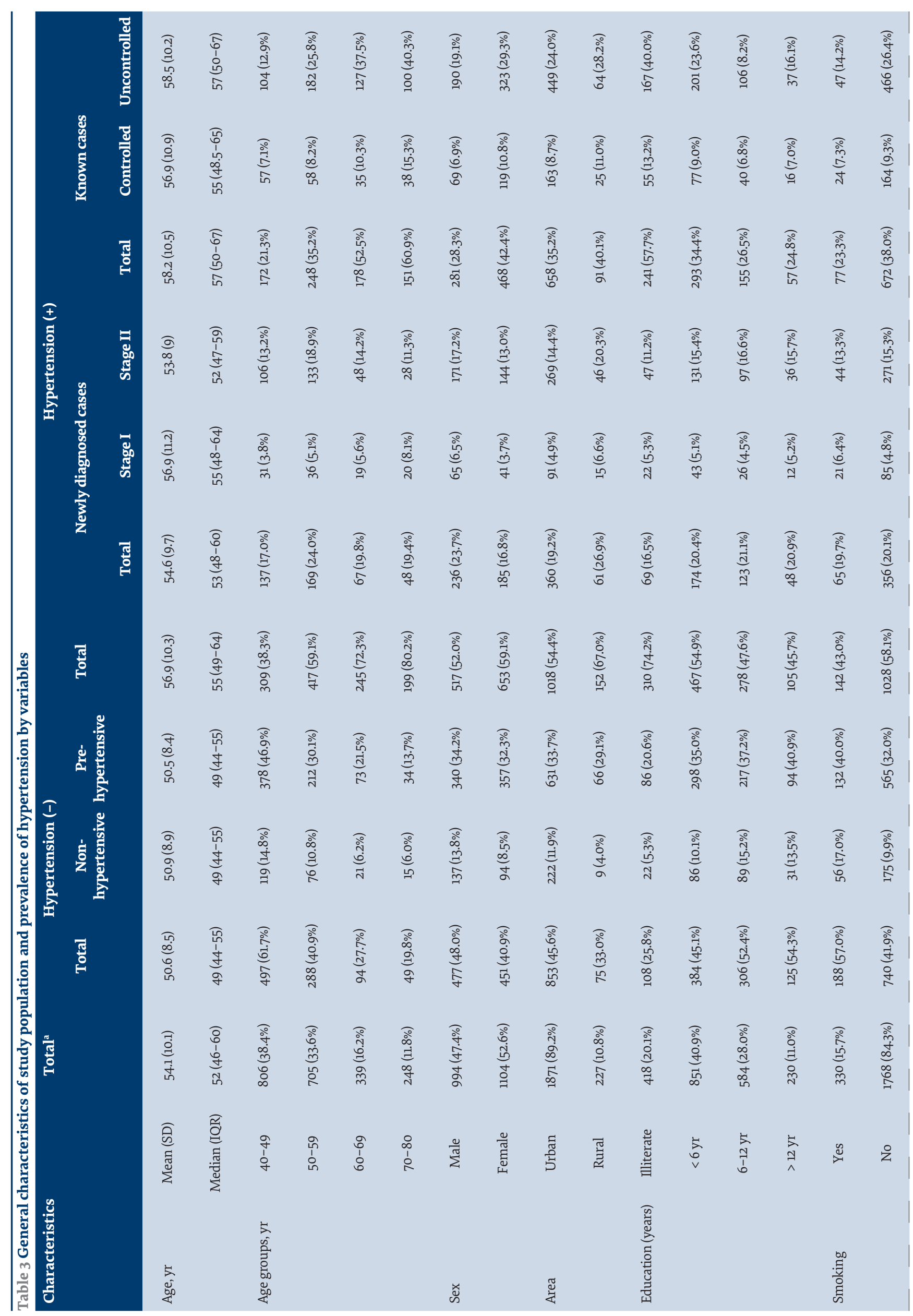




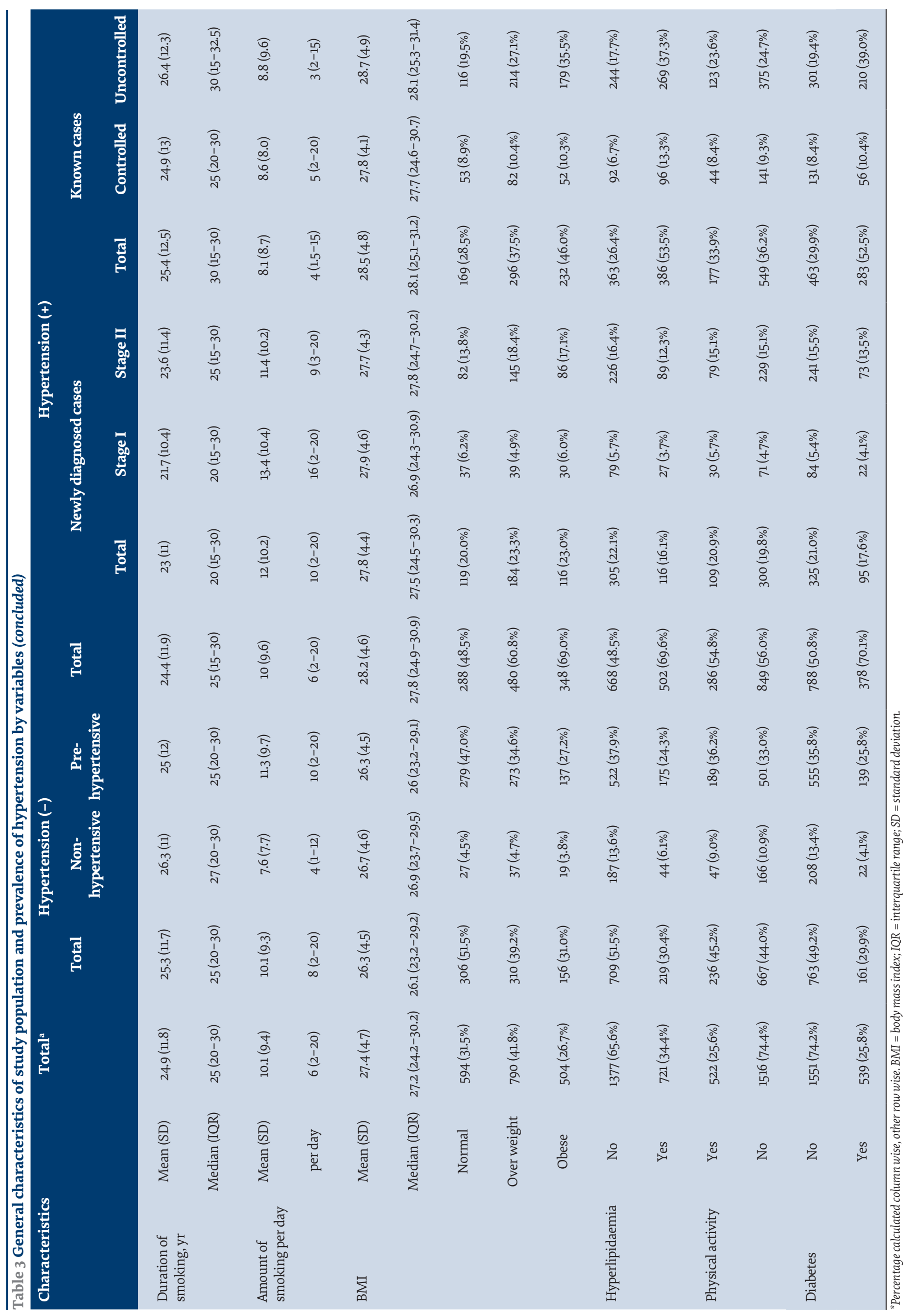




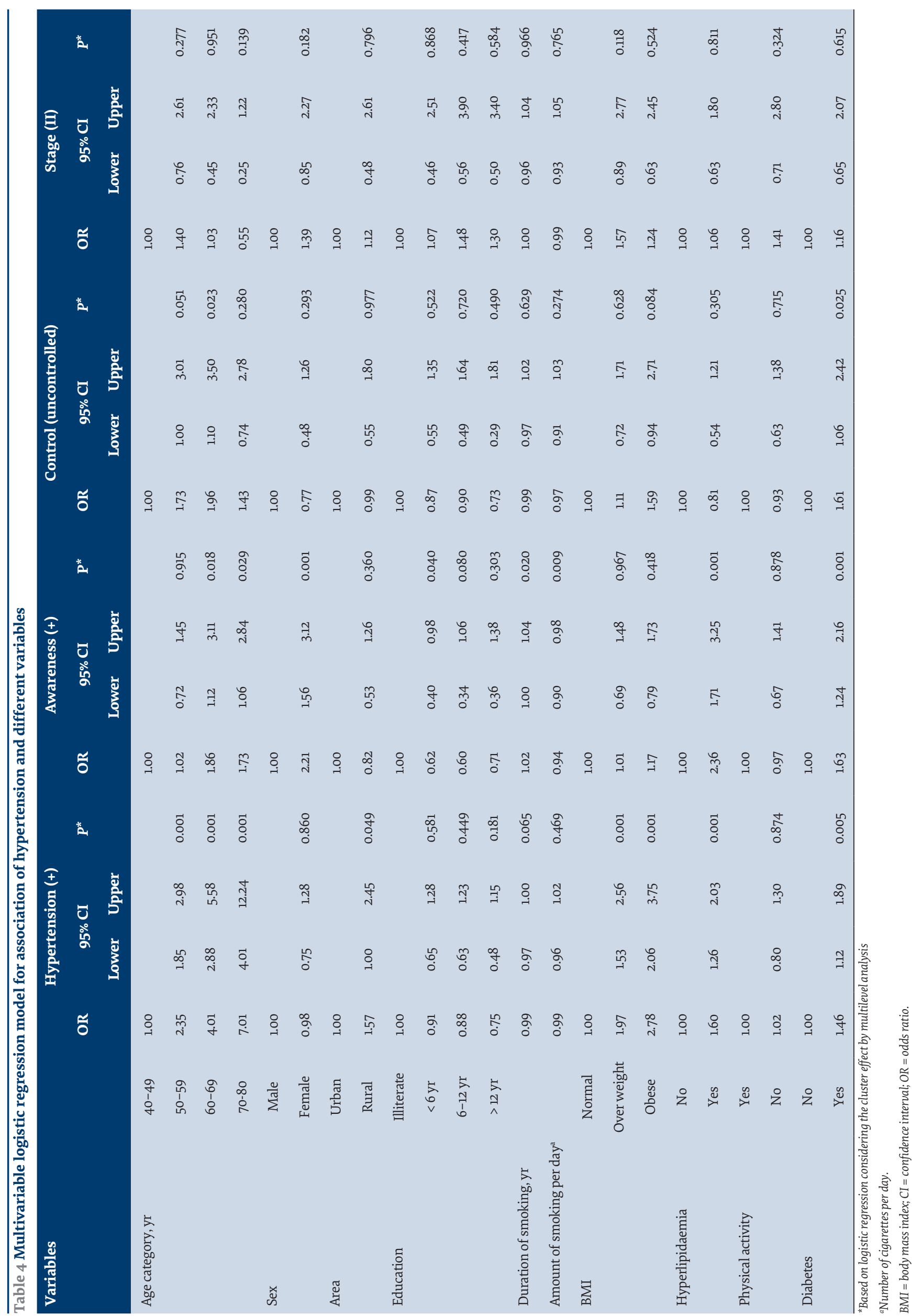




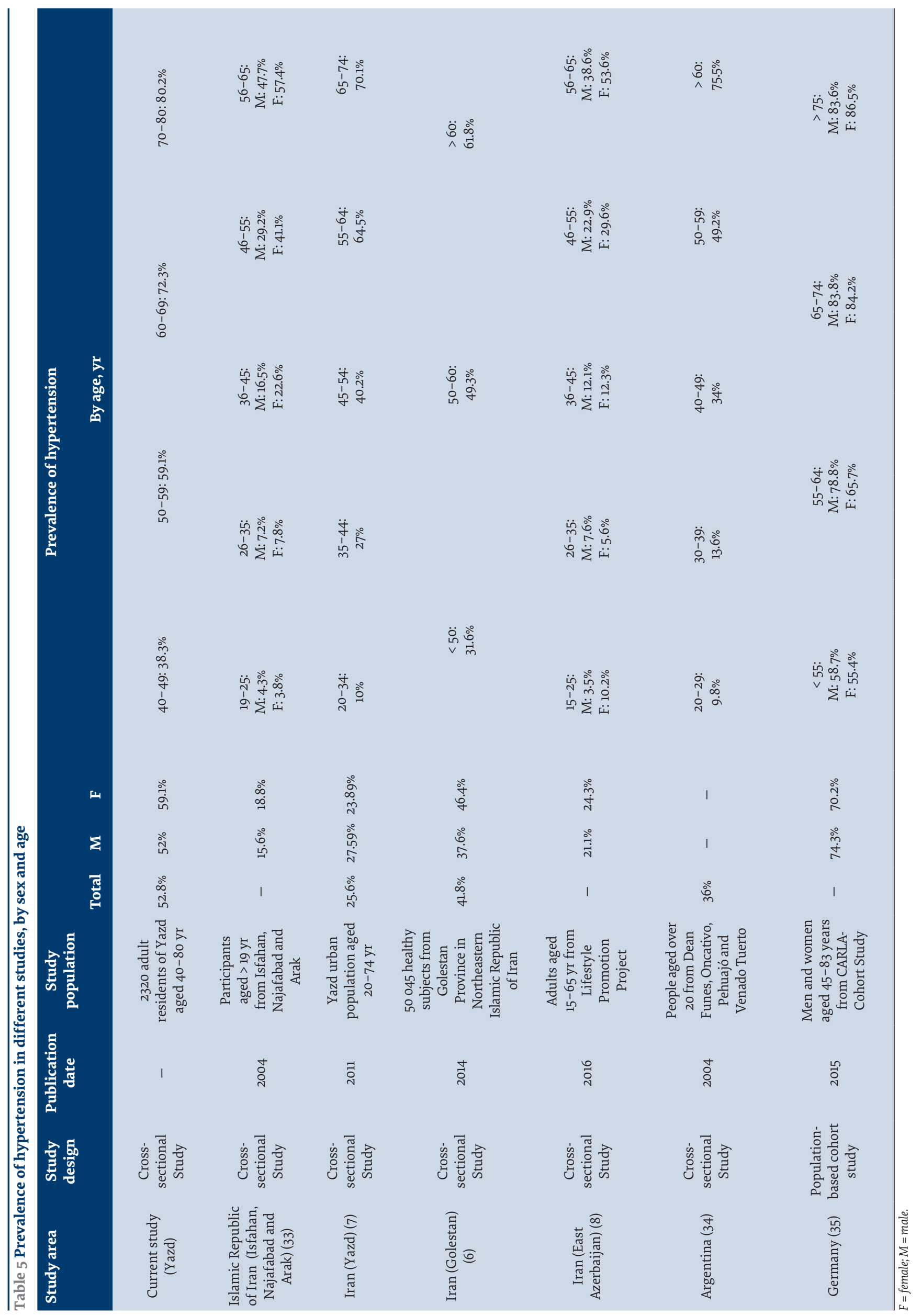


East Asia have shown higher prevalence of hypertension among men (16). A systematic review of 33 studies in South Asia indicated that the male sex is associated with a higher prevalence of hypertension, and only 8 studies showed that hypertension is more prevalent among women (17). Some studies in the Middle East have shown that prevalence of hypertension among both sexes is almost identical or slightly higher among women (18). Likewise, a recent systematic review among the Iranian population revealed that prevalence of hypertension is similar in both sexes (19). The sex difference in our study could be explained by the older age of the study population, since we found that the the effect of older age on hypertension was more substantial among women. It could also be explained by other factors such as vitamin $\mathrm{D}$ deficiency, which is common among women in the Middle East, and this vitamin plays an important role in pathophysiology of hypertension (20). In addition, hormonal changes in postmenopausal women and decreased levels of estrogen cause vasoconstriction (21).

Similar to some other studies (7), women and people aged $\geq 60$ years were more likely to know that they had hypertension in the current study. Men are less likely to seek healthcare services. Therefore, they have a greater risk of being unaware about their health problems in some settings because they pay less attention to their medical condition or have outdoor occupations (22). Moreover, history of diabetes and hyperlipidaemia showed an association with awareness of hypertension in our study. Naturally, older people and those with other medical conditions are more likely to have contact with healthcare professionals during their lifespan, which could explain the higher proportion of awareness in these groups.

The current study showed that both obesity and hyperlipidaemia were associated with hypertension. These results are supported by other studies (23). A study in Macao Special Administrative Region revealed that obese people have 4.5 times higher risk of hypertension compared to normal weight population (24). In addition, there are studies demonstrating that $78 \%$ of essential hypertension in men and $65 \%$ in women is related to excess weight gain (25). It has also been postulated that stimulation of sympathetic activity by high dietary fat and carbohydrate (26) and obesityinduced overactivation of the renin-angiotensinaldosterone system (RAAS) are major biological causes of hypertension in obesity and hyperlipidaemia (25). These all emphasize the importance of weight control in prevention of hypertension.

Our results revealed no significant association between physical activity and hypertension: $45.2 \%$ of normotensive and $54.8 \%$ of hypertensive individuals reported some level of exercise. A recent metaanalysis of prospective cohort studies demonstrated a decreased risk of hypertension in people with increased recreational physical activity. However, the risk did not change with occupational physical activity (27). Physical activity may play a role in decreasing blood pressure by reducing vascular resistance and by influencing the level of activity in the catecholamine and renin angiotensin aldosterone system (28). Although having a physically active lifestyle was more common in patients with hypertension, the association between exercise and hypertension was not significant.

According to our results, people who live in rural areas have a greater risk of hypertension. The geopolitical variation in the distribution of hypertension is diverse. In the Islamic Republic of Iran, different studies have reported conflicting results. Esteghmati et al. reported higher prevalence of hypertension in urban dwellers in 2007 (29), while a cohort study in Golestan Province conducted by Malakzadeh et al. (2004-2008) showed lower risk of hypertension in urban dwellers (6). In addition, some Iranian studies have shown no difference in prevalence of hypertension between urban and rural residents (30). Yazd Province in the centre of the Islamic Republic of Iran has an arid climate and farming is less developed. Migration of most people to cities, fewer job opportunities, lack of welfare resources, and a more stressful lifestyle could be causes of higher prevalence of hypertension in rural areas (31). In addition, lack of systematic programmes to promote general knowledge about appropriate lifestyles in rural areas could be another reason.

Higher level of education has been demonstrated to reduce risk of hypertension in the Islamic Republic of Iran and other countries (6). Education can increase people's awareness about their health, including hypertension, and encourage them to pay more attention to it. Although our multivariable analysis showed no significant association between hypertension and education, the descriptive data showed a considerably higher prevalence of hypertension among people who were illiterate. It should be mentioned that about $25 \%$ of participants in our study were illiterate and only $11 \%$ had an academic education. The number of people who had higher education levels might have been insufficient to show any differences in our study.

In the current study, $17 \%$ of participants reported that they were current smokers and we could not find any significant association between smoking and blood pressure. Nevertheless, many studies have revealed that smoking increases prevalence of hypertension (32). The measurement of tobacco consumption is specific and our data collection procedure did not provide an opportunity for collecting precise information. Anecdotally, smoking tobacco is generally disapproved of in the survey area; therefore, data gathering based on self-reported information may have had a reporting bias.

This study had some limitations. First, this was a cross-sectional study and it cannot predict causality. In addition, we included people aged 40-80 years, and the results cannot be generalized to all age groups living in the study area. Moreover, some risk factors for hypertension such as alcohol consumption, psychological problems and dietary intake were not evaluated. Finally, some of 
our results such as smoking, education, medication and physical activity were based on self-reported information that may have had a reporting bias.

\section{Conclusion}

Hypertension is a major health problem in Yazd. The proportion of those who are not aware of their disorder and the number of cases of uncontrolled hypertension among known cases are considerable. Age, obesity, diabetes, hyperlipidaemia, and living in a rural area are associated with hypertension. Although older age is the main inevitable risk factor for hypertension, there is potential to improve the situation through controlling manageable factors, increasing public awareness and improving care for people with hypertension.

\section{Acknowledgements}

The authors would like to thank Shahid Sadooghi University of Medical Sciences in Yazd, Islamic Republic of Iran, which provided logistic and clinical support to this project. In addition, we would like to thank Dr Sara Hosseini and Dr Zahra Tofighi for participating in data management, interpretation and integration of clinical data.

Funding: None.

Competing interests: None declared.

\section{Hypertension et facteurs associés en République islamique d'Iran : étude en population}

\section{Résumé}

Contexte : L'hypertension est un facteur de risque majeur de maladies cardio-vasculaires. Elle a une forte prévalence dans la Région de la Méditerranée orientale.

Objectifs : Estimer la prévalence de l'hypertension et le niveau de connaissance à cet égard ainsi que les facteurs associés dans une province centale de la République islamique d'Iran.

Méthodes : La présente étude transversale a été réalisée auprès de 2320 adultes âgés de 40 à 80 ans dans la province de Yazd (République islamique d'Iran), en 2010-2011. L'analyse de régression logistique multivariée a été employée pour calculer les odds ratio (OR) permettant d'étudier le lien entre l'hypertension et les facteurs de risque associés. Parmi les sujets remplissant les critères de l'étude, 2098 ont participé aux examens cliniques (taux de réponse : 90,4\%).

Résultats : La prévalence standardisée de l'hypertension selon le sexe et l'âge était de 52,8 \% (intervalle de confiance à $95 \%$ [IC] : 49,6-56,1). Sur les 1170 participants souffrant d'hypertension, 421 avaient été diagnostiqués pour la première fois lors de cette étude. Par conséquent, la proportion de méconnaissance était de 36,0 \% (IC à 95 \% : 33,2-38,8). Parmi les cas connus (749 sur 1 170), 68,5 \% (IC à $95 \%: 65-71,8)$ avaient une tension artérielle non contrôlée. L'âge (OR 70-80 ; 40-50 ans=7,01, IC à $95 \%: 4,01-12,24)$, l'obésité (OR=2,78, IC à $95 \%: 2,06-3,75)$, le diabète (OR=1,46, IC à 95\%:1,12-1,89), l'hyperlipidémie $(\mathrm{OR}=1,60$, IC à $95 \%: 1,26-2,03)$ et l'implantation en zone rurale $(\mathrm{OR}=1,57$, IC à 95 \% : 1,0-2,45) étaient fortement associés à l'hypertension.

Conclusions : Bien que l'âge soit un facteur de risque d'hypertension inévitable, la proportion élevée de méconnaissance, l'hypertension non contrôlée et les facteurs de risque modifiables tels l'obésité, l'hyperlipidémie et le diabète requièrent des stratégies préventives et curatives efficaces.

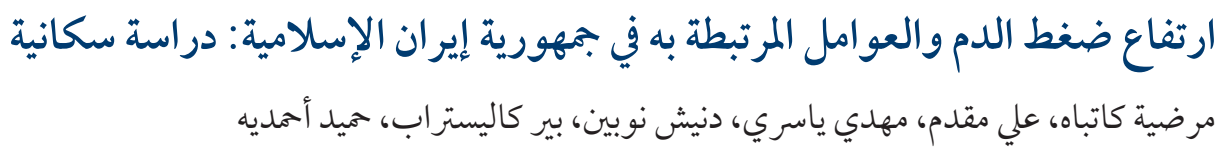

الخلاصة

الخلفية: يُعد ارتفاع ضغط الدم أحد عوامل الخطر الرئيسية للإصابة بأمراض القلب والأوعية الدموية، وهو منتشر بنسبة مرتفعة في إقليم شرق المتوسط.

الأهداف: هدفت الدراسة إلى تقييم مدى انتشار ارتفاع ضغط الدم والعوامل المرتبطة به ومستوى الوعي بشأنه في إحدى المناطق الوسطى في جمهورية إيران الإسلامية.

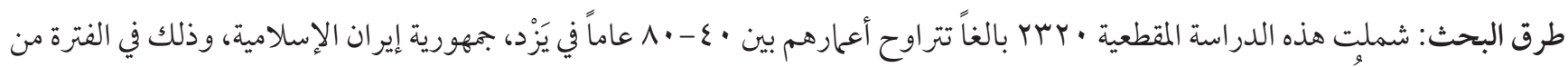

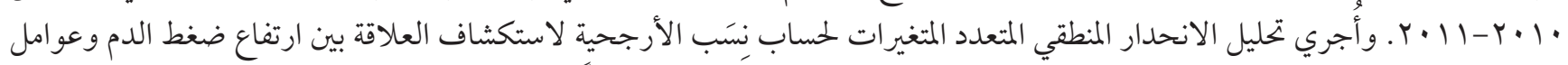

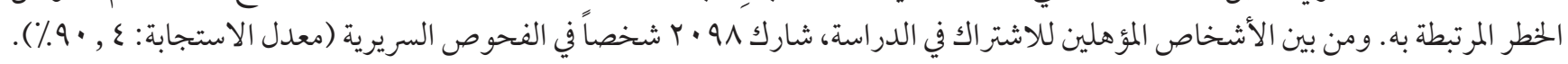




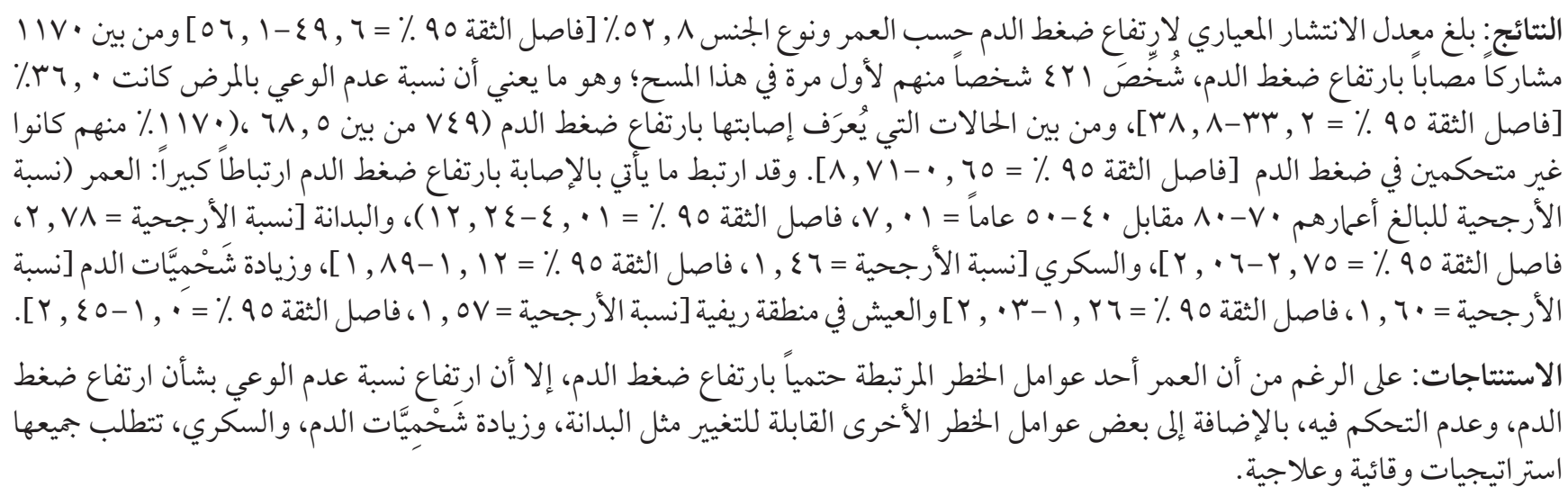

\section{References}

1. Jha V, Garcia-Garcia G, Iseki K, Li Z, Naicker S, Plattner B, et al. Chronic kidney disease: global dimension and perspectives. Lancet. 2013 Jul 20;382(9888):260-72. http://dx.doi.org/10.1016/S0140-6736(13)60687-X PMID:23727169

2. Spence JD, Hammond R. Hypertension and stroke. In: Girouard H, editor. Hypertension and the brain as an end-organ target. Springer; 2016:39-54.

3. Global, regional, and national disability-adjusted life-years (DALYs) for 315 diseases and injuries and healthy life expectancy (HALE), 1990-2015: a systematic analysis for the Global Burden of Disease Study 2015. Lancet. 2017 Sep 16;388(10053):1603-58. http://dx.doi.org/10.1016/So140-6736(17)32130-X PMID:28919118

4. Ruixing Y, Limei Y, Yuming C, Dezhai Y, Weixiong L, Muyan L, et al. Prevalence, awareness, treatment, control and risk factors of hypertension in the Guangxi Hei Yi Zhuang and Han populations. Hypertens Res. 2006 Jun;29(6):423-32. http://dx.doi. org/10.1291/hypres.29.423 PMID:16940705

5. World health statistics 2014. Geneva: World Health Organization; 2015 (https://apps.who.int/iris/bitstream/handle/10665/112738/9789240692671_eng.pdf;jsessionid=5238F85016AE2D6CE7743645EB6BD36A?sequence=1, accessed 30 August 2019).

6. Malekzadeh MM, Etemadi A, Kamangar F, Khademi H, Golozar A, Islami F, et al. Prevalence, awareness and risk factors of hypertension in a large cohort of Iranian adult population. J Hypertens. 2013 Jul;31(7):1364-71. http://dx.doi.org/10.1097/ HJH.obo13e3283613053 PMID:23673348

7. Namayandeh S, Sadr S, Ansari Z, Rafiei M. A cross-sectional study of the prevalence of coronary artery disease traditional risk factors in Yazd urban population, Yazd healthy heart project. Iran Cardiovasc Res J. 2011 Mar;5(1):7-13. https://www.sid.ir/en/ journal/ViewPaper.aspx?id=212840

8. Tabrizi JS, Sadeghi-Bazargani H, Farahbakhsh M, Nikniaz L, Nikniaz Z. Prevalence and associated factors of prehypertension and hypertension in Iranian population: The Lifestyle Promotion Project (LPP). PloS One. 2016 Oct 26;11(10):e0165264. http://dx. doi.org/10.1371/journal.pone.0165264 PMID:27783691

9. Ibrahim MM, Damasceno A. Hypertension in developing countries. Lancet. 2012 Aug 11;380(9841):611-9. http://dx.doi.org/10.1016/ So140-6736(12)60861-7 PMID:22883510

10. Haghdoost AA, Sadeghirad B, Rezazadehkermani M. Epidemiology and heterogeneity of hypertension in Iran: a systematic review. Arch Iran Med. 2008 Jul;11(4):444-52. http://dx.doi.org/o8114/AIM.0017 PMID:18588378

11. Katibeh M, Ziaei H, Pakravan M, Dehghan MH, Ramezani A, Amini H, et al. The Yazd Eye Study-a population-based survey of adults aged 40-80 years: rationale, study design and baseline population data. Ophthalmic Epidemiol. 2013;20(1):61-9. http://dx. doi.org/10.3109/09286586.2012.744844 PMID:23350557

12. Chobanian AV, Bakris GL, Black HR, Cushman WC, Green LA, Izzo JL Jr, et al. Seventh report of the Joint National Committee on Prevention, Detection, Evaluation, and Treatment of High Blood Pressure. Hypertension. 2003 Dec;42(6):1206-52. http://dx.doi. org/10.1161/01.HYP.0000107251.49515.c2 PMID:14656957

13. Motiei-Langarodi SH, Ghoriashi SG, Asghari F, Kavian K. Pulse and blood pressure in school-age children in Qazvin. J Qazvin Univ Med Sci. 2000;4(1):56-62. http://journal.qums.ac.ir/article-1-548-en.html

14. Buford TW. Hypertension and aging. Ageing Res Rev. 2016 Mar;26:96-111. http://dx.doi.org/10.1016/j.arr.2016.01.007 PMID: 26835847

15. Lu FH, Tang SJ, Wu JS, Yang YC, Chang CJ. Hypertension in elderly persons: its prevalence and associated cardiovascular risk factors in Tainan City, southern Taiwan. J Gerontol A Biol Sci Med Sci. 2000 Aug;55(8):M463-8. http://dx.doi.org/10.1093/ gerona/55.8.m463 PMID:10952370

16. Wu Y, Huxley R, Li L, Anna V, Xie G, Yao C, et al. Prevalence, awareness, treatment, and control of hypertension in China: data from the China National Nutrition and Health Survey 2002. Circulation. 2008 Dec 16;118(25):2679-86. http://dx.doi.org/10.1161/ CIRCULATIONAHA.108.788166 PMID:19106390 
17. Neupane D, McLachlan CS, Sharma R, Gyawali B, Khanal V, Mishra SR, et al. Prevalence of hypertension in member countries of South Asian Association for Regional Cooperation (SAARC): systematic review and meta-analysis. Medicine. 2014 Sep;93(13):e74. http://dx.doi.org/10.1097/MD.0000000000000074 PMID:25233326

18. Motlagh B, O'Donnell M, Yusuf S. Prevalence of cardiovascular risk factors in the Middle East: a systematic review. Eur J Cardiovasc Prev Rehabil.. 2009 Jun;16(3):268-80. http://dx.doi.org/10.1097/HJR.obo13e328322ca1b PMID:19398913

19. Mirzaei M, Moayedallaie S, Jabbari L, Mohammadi M. Prevalence of hypertension in Iran 1980-2012: a systematic review. J Tehran Heart Cent. 2016 Oct 3;11(4):159-67. PMID:28496506

20. Vimaleswaran KS, Cavadino A, Berry DJ, Jorde R, Dieffenbach AK, Lu C, et al. Association of vitamin D status with arterial blood pressure and hypertension risk: a mendelian randomisation study. Lancet Diabetes Endocrinol. 2014 Sep;2(9):719-29. http://dx. doi.org/10.1016/S2213-8587(14)70113-5 PMID:24974252

21. Te Riet L, van Esch JH, Roks AJ, van den Meiracker AH, Danser AH. Hypertension: renin-angiotensin-aldosterone system alterations. Circ Res. 2015 Mar 13;116(6):960-75. http://dx.doi.org/10.1161/CIRCRESAHA.116.303587 PMID:25767283

22. Bertakis KD, Azari R, Helms LJ, Callahan EJ, Robbins JA. Gender differences in the utilization of health care services. J Fam Pract. 2000 Feb;49(2):147-52. PMID:10718692

23. Hendriks ME, Wit FW, Roos MT, Brewster LM, Akande TM, de Beer IH, et al. Hypertension in sub-Saharan Africa: cross-sectional surveys in four rural and urban communities. PLoS One. 2012;7(3):e32638. http://dx.doi.org/10.1371/journal.pone.0032638 PMID:22427857

24. Ke L, Ho J, Feng J, Mpofu E, Dibley MJ, Feng X, et al. Modifiable risk factors including sunlight exposure and fish consumption are associated with risk of hypertension in a large representative population from Macau. J Steroid Biochem Mol Biol. 2014 Oct;144 Pt A:152-5. http://dx.doi.org/10.1016/j.jsbmb.2013.10.019. PMID:24189545

25. Hall JE, do Carmo JM, da Silva AA, Wang Z, Hall ME. Obesity-induced hypertension: interaction of neurohumoral and renal mechanisms. Circ Res. 2015 Mar 13;116(6):991-1006. http://dx.doi.org/10.1161/CIRCRESAHA.116.305697 PMID:25767285

26. Rocchini AP, Yang JQ, Gokee A. Hypertension and insulin resistance are not directly related in obese dogs. Hypertension. 2004 May;43(5):1011-6. http://dx.doi.org/10.1161/01.HYP.0000123073.48855.e9 PMID:15007033

27. Huai P, Xun H, Reilly KH, Wang Y, Ma W, Xi B. Physical activity and risk of hypertension: a meta-analysis of prospective cohort studies. Hypertension. 2013 Dec;62(6):1021-6. http://dx.doi.org/10.1161/HYPERTENSIONAHA.113.01965 PMID:24082054

28. Cornelissen VA, Fagard RH. Effects of endurance training on blood pressure, blood pressure-regulating mechanisms, and cardiovascular risk factors. Hypertension. 2005 Oct;46(4):667-75. http://dx.doi.org/10.1161/01.HYP.0000184225.05629.51 PMID:16157788

29. Esteghamati A, Meysamie A, Khalilzadeh O, Rashidi A, Haghazali M, Asgari F, et al. Third national Surveillance of Risk Factors of Non-Communicable Diseases (SuRFNCD-2007) in Iran: methods and results on prevalence of diabetes, hypertension, obesity, central obesity, and dyslipidemia. BMC Public Health. 2009 May 29;9:167. http://dx.doi.org/10.1186/1471-2458-9-167. PMID:19480675

30. Janghorbani M, Amini M, Gouya MM, Delavari A, Alikhani S, Mahdavi A. Nationwide survey of prevalence and risk factors of prehypertension and hypertension in Iranian adults. J Hypertens. 2008 Mar;26(3):419-26. http://dx.doi.org/10.1097/HJH.obo13e3282f2d34d PMID:18300850

31. Salavati A. The Survey on Migration of Rural Populations to Urban inIranian Villagers: A Case Study in Naein Region in theCenter of Iran. Int J Soc Sci Humanity. 2013 Jan;3(1):30-32. http://dx.doi.org/10.7763/IJSSH.2013.V3.187

32. Virdis A, Giannarelli C, Neves MF, Taddei S, Ghiadoni L. Cigarette smoking and hypertension. Curr Pharm Des. 2010;16(23):251825. http://dx.doi.org/10.2174/138161210792062920 PMID:20550499

33. Sadeghi M, Roohafza HR, Kelishadi R. Blood pressure and associated cardiovascular risk factors in Iran: Isfahan Healthy Heart Programme. Med J Malaysia. 2004 Oct;59(4):460-7. PMID:15779578

34. de Sereday MS, Gonzalez C, Giorgini D, De Loredo L, Braguinsky J, Cobenas C, et al. Prevalence of diabetes, obesity, hypertension and hyperlipidemia in the central area of Argentina. Diabetes Metab. 2004 Sep;30(4):335-9. PMID:15525876

35. Lacruz ME, Kluttig A, Hartwig S, Loer M, Tiller D, Greiser KH, et al. Prevalence and incidence of hypertension in the general adult population: results of the CARLA-Cohort Study. Medicine (Baltimore). 2015 Jun;94(22):e952. http://dx.doi.org/10.1097/ MD.0000000000000952 PMID:26039136 